\title{
阿蘇外輪山本谷越産の普通輝石
}

\section{Augite from Hontanigoe of Aso-Caldera, Kumamoto}

Prefecture

\section{松 本 幡 郎 (Hatao Matsumoto)}

\begin{abstract}
The crystals of augite were found in hypersthene augite andesite lava at Hontanigce of Aso-caldera, Kumamoto Prefecture. This area is composed of seven lavas of two-pyroxene andesite and its agglomerates, which are cbserved at the inside wall of somma. At Hontanigoe, a dyke is observed which strikes $N 70^{\circ} \mathrm{E}$. This dyke is hornblende andesite and is very rich in large hornblende phenocrysts that often attain 1 or $2 \mathrm{~cm}$. in length.

The crystals of augite are greenish black in colour and idiomorphic with crystal faces $\mathrm{a}(100), \mathrm{b}(010), \mathrm{m}(110)$, and $\mathrm{s}(\overline{1} 11)$, as shown Fig. I. The crystals of augite with shown a interpenetration twin have the following crystal faees; a (100), b (010), c $(001), \mathrm{m}(110), \mathrm{s}(\overline{1} 11)$, and $\mathrm{p}(\overline{1} 01)$, as shown in Fig. 2.

This augite has the follcwing opitical properties: $\alpha=\mathrm{I} .686-\mathrm{I} .689, \beta=$ I. 692-I.694, $\gamma=$ I. $710-\mathrm{I} .713,2 \mathrm{~V}(+)=57^{\circ}-59^{\circ}$. Colour is yellowish green and its pleochroism is weak in thin section. $\mathrm{X}=$ pale green, $\mathrm{Y}=$ pale ycllow, $Z=$ yellowish pale green. The crystals of augite show the hourglass texture and develop the zonal structure. Inclusions of augite are irregular magnetite and idiomcrphic plagioclase (An. 57-62\%).

The result of chemical analysis is shcwnin Table I. It is characteristic in its chemical constitution that this augite is rich in $\mathrm{Al}_{2} \mathrm{O}_{3}$ and poor in $\mathrm{CaO}$. The writer presumes that this is related to the type of twinning and its opitical properties. The formula of the augite W. A. Deer \& $\mathrm{L}$. R. Wager follow: $(\mathrm{XY})_{1.970}\left((\mathrm{Si}, \mathrm{Al})_{2} \mathrm{O}_{6}\right)$. The weight $\%$ as wollastonite $\left(\mathrm{CaSiO}_{3}\right)$, enstatite $\left(\mathrm{MgSiO}_{3}\right)$, and ferrosilite $\left(\mathrm{FeSiO}_{3}\right)$ are Wo: $39.13 \%, \mathrm{En}$ : $\mathbf{3 4 . 7 8} \%$, Fs: $26.19 \%$. In Table 2 is the constitutions as metasilicate.

In addition to, the Table 3 is the bulk chemical composition of the hypersthene augite andesite and the chemical composition of the hypersthene hyenccryst.
\end{abstract}

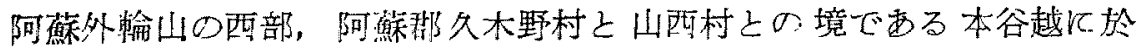
て，普通䖯石の美晶定採集する事が出来る。当地域の地質は，久木野村側 でるる外榆山の内壁飞七枚の種々存 two pyroxene andesite 厄熔岩流 と集塊岩より成り，本路石は最上部の熔岩である，hypersthene augite

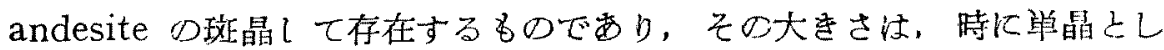
て $1.3 \mathrm{~cm}$ に達する事がする。との揢岩は上部に於て权状節理が発達し

1）棓脎以ついては後日発衰の予定。 
て居り，その節理の走向及び倾斜は $\mathrm{N} 40^{\circ} \cdot \mathrm{W}, \mathrm{S} 15^{\circ}$ 一゙西る。媔度，本谷

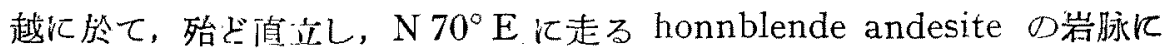

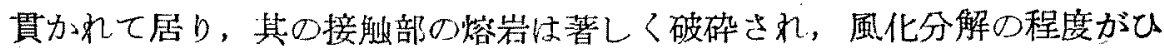

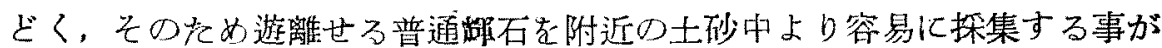
出来る。

普通輝石の結晶 結晶の表面は赤褐色比酸化しているものもあるが，内 部は皆緑黑色である。結晶には学晶, 双晶它なすものの外に, 数個の結晶 が集つて椱雑热聚含体を形成して居る。单晶の結晶は短柱局平状ですつて 杜面では a (100) 最も発達し，b(010) は之次ぎ，m(110) は狭い。端 面は c.s.s.より成り c (001) が著しく大き?s(T11) は割に小さん（Fig.
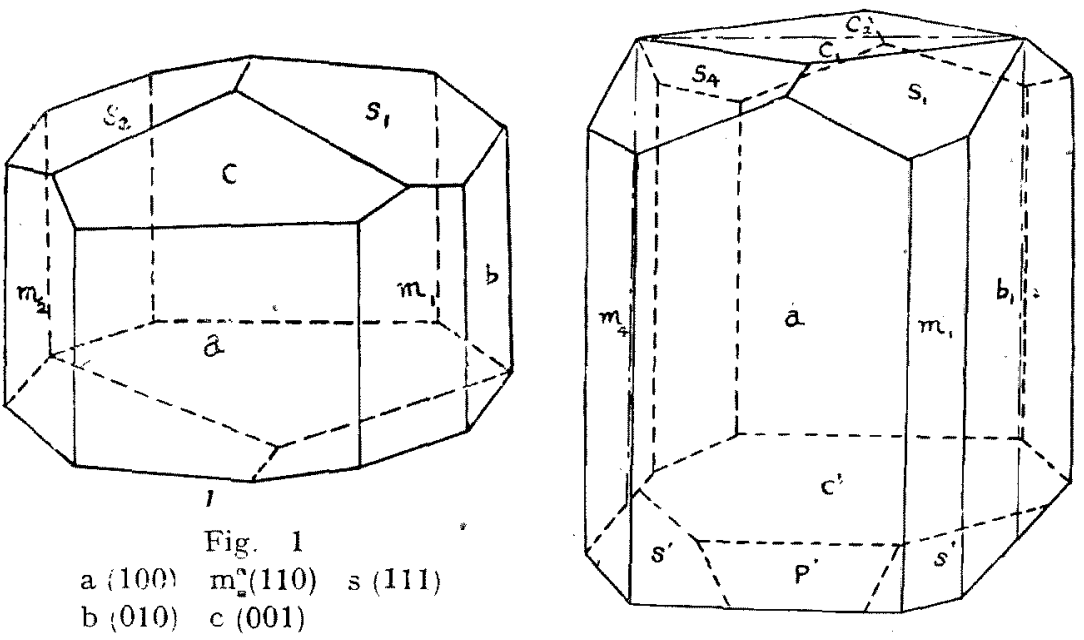

Fig. 2

a $(100) \mathrm{m}(110) \mathrm{s}(\overline{1} 11)$

$\mathrm{b}(010) \quad \mathrm{c}(001) \quad \mathrm{p}(101)$

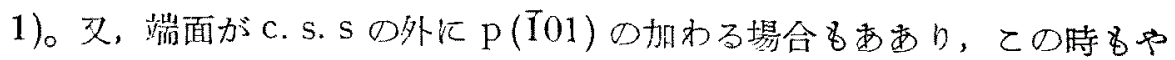
はり $\mathrm{c}$ が最も発達し $\mathrm{p}>\mathrm{s}$ の順序である。欢晶は、老胚晶面之する貫入双 晶をなしているものが非常に多く，一見斜方晶系の対㛵を有するかの加き

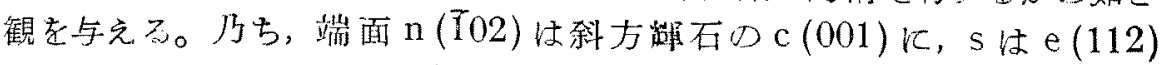

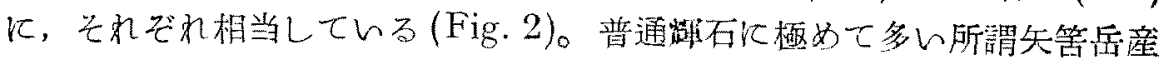
の欢晶は一個名存在してい斿い。

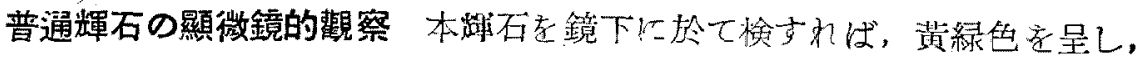

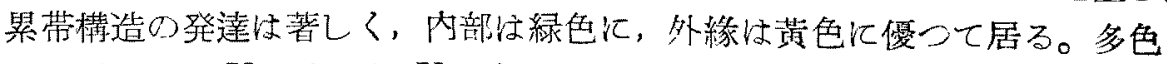

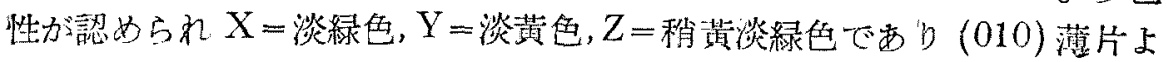




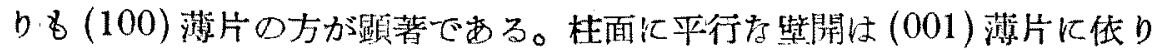

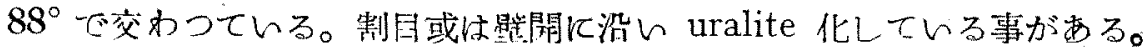
包塞物としては粒状又心聭状の magnetite, 自形枉状の plagioclase (An. $57 \sim 62 \%$ )，及び赤裀色の鉄の酸化物，黒褐色の班璃定認める。所謂砂時

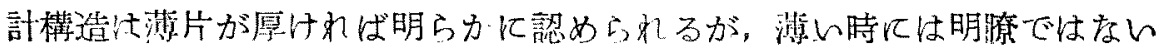
(Fig. 3)。複展析外外部の方が內部

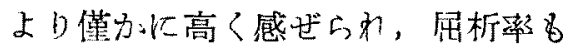
同㥞汇外部の方が一般汇高い。屈析 率は浸液法で測定の結果 $\alpha=1.686$ $1.689, \beta=1.692 \sim 1.694, \gamma=1.710$ 〜1.713であり，光軸角は自在㿿転 台で测つた結果 $2 \mathrm{~V}(+)=57^{\circ} \sim 59^{\circ}$ で声り，属析率之逆に內部の力が外 緣部ようも，その光䡃角は大きい傾 向传る。份，本却石の比重を测定 しを結果は $3.317\left(4^{\circ} \mathrm{C}\right)$ である。

普通輝石の化學組成 $a, m, b, c$, 面上り成る单晶圭選び，之老砕いて。 ツレ一液にて選別し，馬蹄形強磁石 を使用して磁鉄鉱交含む80除去 L，次で双眼顕微镜下にて識別し，

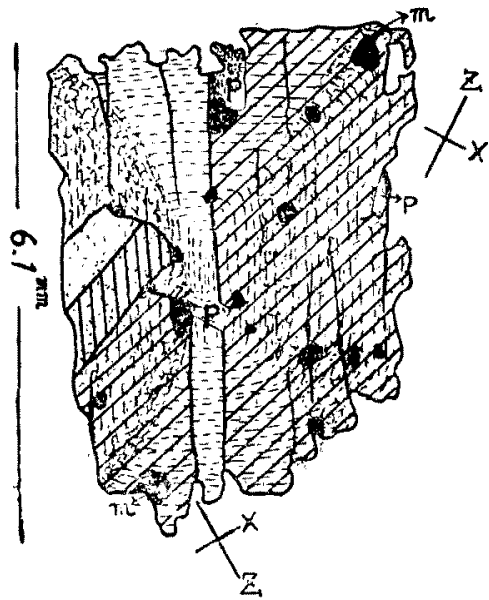

Fig. 3 唀入双晶及び砂時計構造を示す 普通数石 $(010)$

$$
\mathrm{p} \text {; 斜長不 } \mathrm{m} \text {; 磁鉄鉱 }
$$

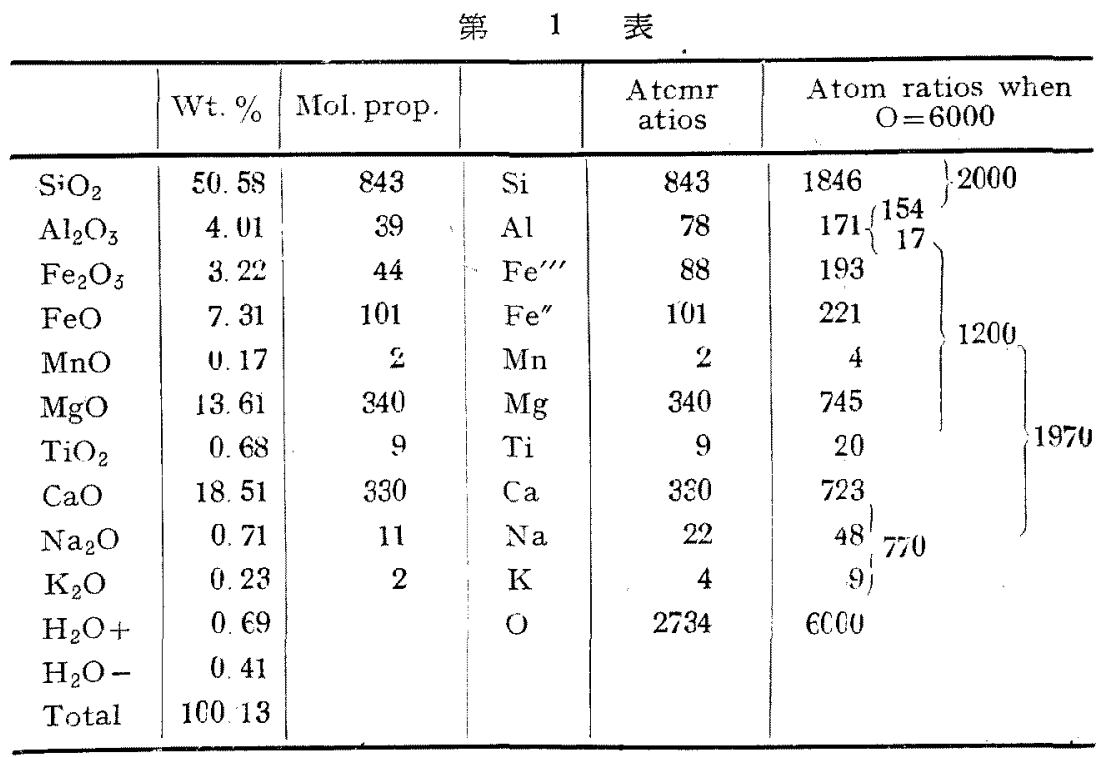


精選せるものを，分析資料儿供した。其の結果，及びそれから得られた分 子比，原于比は第 1 表经示す通りである1。

普通輝石の化學式 普通悺石の化学式海しては，F. machatschki の 化学式き，B，E，Warren 及び J. Biscoe の化学式引，W. A. Deer 及び L. R. Wager の化学式 ${ }^{4}$ が代表的度ものであり，その条式に做つて表わ すと前頁の如くになる。

1) F. Machatschki $\sigma$ 化学式

$\mathrm{XY}(\mathrm{Si}, \mathrm{Al})_{2}(\mathrm{O}, \mathrm{OH}, \mathrm{F})_{6}$

但 L, $\mathrm{X}=\mathrm{Ca},{ }^{\mathrm{N} a},(\mathrm{~K}),(\mathrm{Mn}),(\mathrm{Mg}) ., \mathrm{Y}=\mathrm{Mg}, \mathrm{Fe}, \mathrm{Mn}, \mathrm{Al},-(\mathrm{Zn})$, (Ti).

$\mathrm{X}_{0.770} \mathrm{Y}_{1 \cdot 200}(\mathrm{Si}, \mathrm{Al})_{2 \cdot 000}(\mathrm{O})_{6 \cdot 000}$

2) B. E, Warren 及び J, Biscoe $の$ 化学式

$\mathrm{X}_{\mathrm{In}} \mathrm{Y}_{2-\mathrm{m}}(\mathrm{Si}, \mathrm{Al})_{2}(\mathrm{O}, \mathrm{OH}, \mathrm{F})_{6}$

但 $L, X=\mathrm{Ca}, \mathrm{Na}, \mathrm{K} ., \mathrm{Y}=\mathrm{Mg}, \mathrm{Fe}, \mathrm{Al}, \mathrm{Ti}, \mathrm{Li}$.

$\mathrm{X}_{0.770} \mathrm{Y}_{1.200}(\mathrm{Si}, \mathrm{Al})_{2.000}(\mathrm{O})_{6.030}$

3) W, A, Deer 度び L, R, Wagen の化学式

$(\mathrm{XY})_{2}\left[(\mathrm{Si}, \mathrm{Al})_{2} \mathrm{O}_{6}\right]$

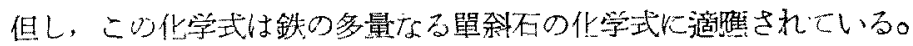

$(\mathrm{XY})_{1.970}\left[(\mathrm{Si}, \mathrm{Al})_{2} \mathrm{O}_{6}\right]$

上の三式に然て $(\mathrm{Si}, \mathrm{Al}, \mathrm{Ti}$,$) ：O 比は何れる2:6となり一致するが$ $(\mathrm{Ca}, \mathrm{Na}, \mathrm{K})$ 上 $\left(\mathrm{Mg}, \mathrm{Fe}^{n}, \mathrm{Fe}^{\prime \prime \prime}, \mathrm{Mn}, \mathrm{Ti}\right)$ の比怯 F. Machatschki $\sigma$ 式k

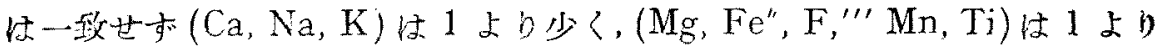

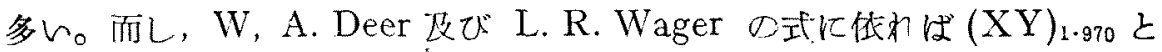
なり略 2 㩐しくなり，満足すると云える。

Wo-En-Fs 圖 本胡石考 wollastonite $\left(\right.$ Wo. $\left.=\mathrm{Ca} \mathrm{Si} \mathrm{O}_{3}\right)$, enstatite $\left(\mathrm{En} .=\mathrm{MgSiO}_{3}\right)$, 及び ferrosilite $\left(\mathrm{Fs} .=\mathrm{FeSiO}_{3}\right)$ の重量比率で示す三角 形国に投影して見ると化学成分関䌽は明になる(Fig. 4)。中兴部に diop-

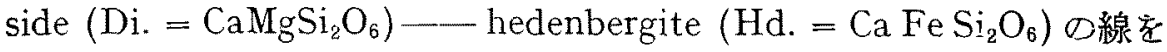

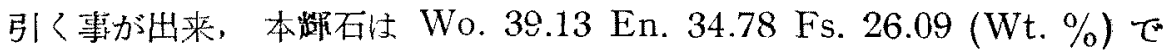
あり，Di-Hd線占り下部に落ちる。この事は，Machatschki $\sigma$ 化学式

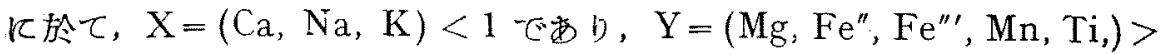
1 となつを結留と同じ事走示すものであり，Machatschki の化学式を満

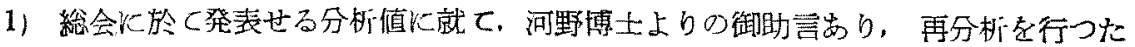
結果で嵓る。

2) F.Machatschki, Zeit. Krist. 71, 229, 1929.

3) B. E. Warren and J. Bisoe, Zeit. Krist. 80, 401, 1931

4) W. A. Deer and L.R.Wager,Min Mag. 5, 16, 1938 
足す心゙を多のは当然 $\mathrm{D} i-\mathrm{Hd}$ 線 上汇落ちる成分の伢石のみであ り。 河野博士 ${ }^{11}$ 北原氏 ${ }^{2)}$ の指摘 されて居的れる様, 晋通踪石の 化学式仕 Machatschki $\odot$ XY $(\mathrm{Si}, \mathrm{Al})_{2} \mathrm{O}_{6}$ は不適当であり，實 ろ W. A. Deer 及び L. R. Wager O)化学式 $(\mathrm{XY})_{2}\left[(\mathrm{Si}, \mathrm{A} !)_{2} \mathrm{O}_{6}\right]$ で表加す方が要当であると考え る。富田博上 ${ }^{3}$ はアルカリ岩中 の普通路石と，カルクアルカリ 岩坵の普通綿石考Wo-En-Fs 园に表各せる場合，アルカリ岩 中心普通践石は Wo 分子代富 み $\mathrm{Di}-\mathrm{Hd}$ 線上り上部飞落占， カルクアルカリ岩中のも估 Di-Hd線上り下为化落ちる事 を述べられている。

本踽石の母岩は後述の如くに Bandose のカルクアルカり岩 で西り，同氏の述べられた如く K. Di-Hd楾上り下方に落ちる。 構成分子 祽津俶䋸博士及 び Washington 氏依る化学 成分上 $b$ 構成分子のメ夕结酸塩 分子算出する方法が従来行わ れている ${ }^{4}$ 其の方法にて構成分 子学出すると第 2 表化示吉樈 にする。此の表に依ると透蛹石 分子 $76.10 \%$ 上云万多量の成分 を含み，唋耀石分子は少量存在

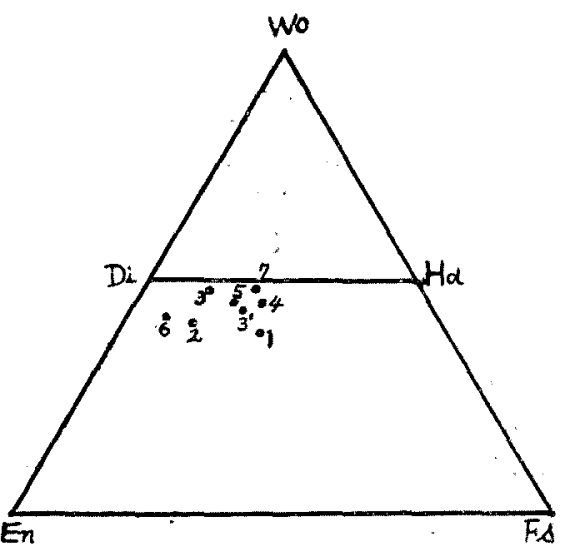

Fig. 4

Wo-En-Fs 三触 (靁量比)

1. 本公越産 (烃本)

2. 聖山産(河野)

3. 輪䒚座(線色)

3." " 黑毛) (北原)

4. 駒尔岳座 (神津，濑曰)

5. 米山座 (久野, 田和專)

6. 西子岳座(大橋)

7. 政努山産 (原口)

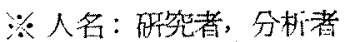

\begin{tabular}{c|c} 
第 2 & 表 \\
\hline & wt. \% \\
\hline $\mathrm{Na} \mathrm{Fe} \mathrm{Si}_{2} \mathrm{O}_{6}$ & $5 .{ }^{\prime}$ \\
$\mathrm{Ca} \mathrm{Mg} \mathrm{Si} \mathrm{O}_{6}$ & 76.10 \\
$\mathrm{Mg} \mathrm{Si} \mathrm{O}$ & 0.54 \\
$\mathrm{Fe} \mathrm{Si} \mathrm{O}$ & 7.13 \\
$\mathrm{Mn} \mathrm{Si} \mathrm{O}_{3}$ & 0.14 \\
$\mathrm{Fe}_{2} \mathrm{O}_{3}$ & $\mathbf{5 . 6 3}$ \\
$\mathrm{Al}_{2} \mathrm{O}_{3}$ & 4.25 \\
$\mathrm{Ti} \mathrm{O}_{2}$ & 0.25 \\
\hline
\end{tabular}
するが， ヘデン粘石分于は存在

1) 河野義礼，岩礛，22，61 69, 昭 14 .

2) 高楚純一，北原順一：岩磄，35，15 23，昭 26 .

3) 富田 澾：圷質学雜誌，44，p. 953，昭 12 .

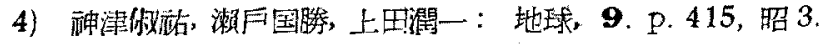


しない。Larsen 亿び Irving ${ }^{1)}$ は San guan 地域 $\sigma$ 諸種从山岩中の各種

\begin{tabular}{|c|c|c|}
\hline & 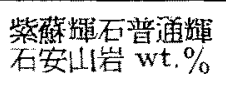 & 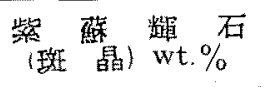 \\
\hline $\mathrm{SiO}_{2}$ & 54.23 & 52.42 \\
\hline $\mathrm{Al}_{2} \mathrm{O}_{3}$ & 17. 85 & 1. 43 \\
\hline $\mathrm{Fe}_{2} \mathrm{O}_{2}$ & 3.81 & 1.17 \\
\hline $\mathrm{FeO}$ & 5.78 & 19.49 \\
\hline $\mathrm{MnO}$ & 0.15 & 0.89 \\
\hline $\mathrm{MgO}$ & 3. $7 \mathrm{~L}$ & 23.08 \\
\hline $\mathrm{CaO}$ & 8. $3 E$ & 0.94 \\
\hline $\mathrm{Na}_{2} \mathrm{O}$ & 2. 46 & \\
\hline $\mathrm{K}_{c} \mathrm{O}$ & 1.37 & \\
\hline $\mathrm{H}_{2} \mathrm{O}+$ & 0.89 & 0.52 \\
\hline $\mathrm{H}_{2} \mathrm{O}-$ & 0.66 & 0.24 \\
\hline $\mathrm{P}_{2} \mathrm{O}_{5}$ & 0.18 & \\
\hline $\mathrm{TiO}_{2}$ & 0.25 & 0.21 \\
\hline \multirow[t]{2}{*}{ Total } & 99.71 & 100.59 \\
\hline & $\begin{array}{l}\text { II. } 4.4 .4 \sim 5 \\
\text { Bandose }\end{array}$ & $\begin{array}{c}\mathrm{X}_{0.994} \mathrm{SiO}_{3} \\
\text { 但 } \mathrm{X}=\mathrm{Fe} \mathrm{e}^{\prime \prime}, \mathrm{Fe} \mathrm{e}^{\prime \prime}, \\
\mathrm{Mn}, \mathrm{MgC \textrm {C }}, \mathrm{Al} \\
\mathrm{Si}=\mathrm{Si}, \mathrm{Ti}, \mathrm{Al} .\end{array}$ \\
\hline
\end{tabular}

战石化学分析を行い， 又夕珪酸篮分子一考算出 $L$, clinohypersthene 分于比富む口福温岩 であり，鼠出温度の隆 下寸るに良二て減少す ると沭へ，梪石安山岩 の晶出する温度では clinohypersthene分子 老 $24 \%$ 会已と法つて るが木辢石の母岩の珪 酸は $54 \%$ のもので西 b，之の妨与晶普通輝石 $\varnothing$ clinohypersthene 分子は $7.8 \%$ にすを极 レものである。

\section{本輝石の母岩及び共} 存紫蘇輝石 本辉石点 含充岩石小前述の如々 hypersthene augite

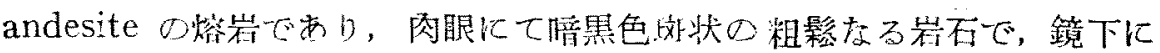

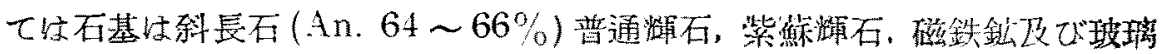
質上り成り，構造忧 hyalopilitic である。斑晶としては今矿究対䊈とせ

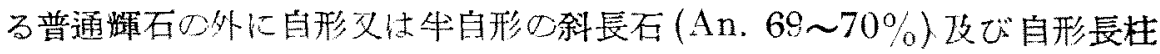
状の紫偨輝石 $(\alpha=1.695 \beta=1.704 \gamma=1.709 \gamma-\alpha=0.0162 \mathrm{~V}(-)=$

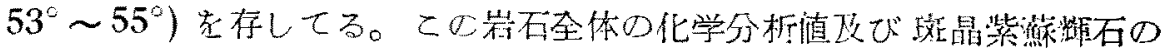

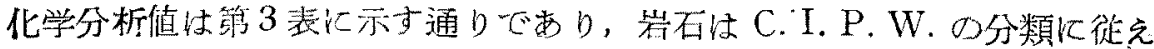

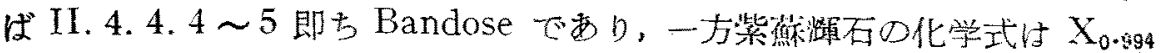

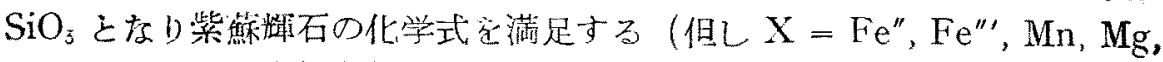
$\mathrm{Ca}, \mathrm{Al}, \mathrm{Si}=\mathrm{Si}, \mathrm{Ti}, \mathrm{Al}$ )

\section{結語}

本谷越座の嘲石飞化学分析せる結果 $\mathrm{CaO}$ の少量であ； $\mathrm{Al}_{2} \mathrm{O}_{3}$ の多い值 走す。本蝚石が多色性を有する一因としては $\mathrm{CaO}$ 少く $\mathrm{Fe}_{3} \mathrm{O}_{3}$ が多く，

1) E. S. Larsen and J. Irving, Amer. Min., Vol. 21, p. 694, 1936 
灭アルカリの若干多い結果に依ると考えられるが明らかではい。其の外，

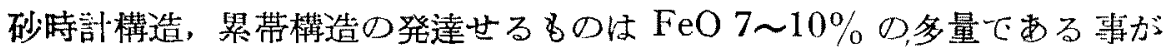

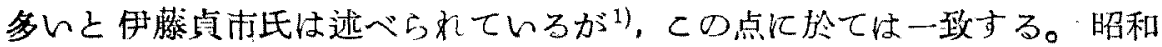
27 年大分大学にて開催された日本地質学会総会に於て発表した後，この方 面の問題に非常を関心を持つて居られる゙方々よりの很問い合せに答えて乱 稿ながらパン考取つを次第である。

向稿を終るに当り，分析值について有益なる御助言を睗つた商工省技官河野博七，並

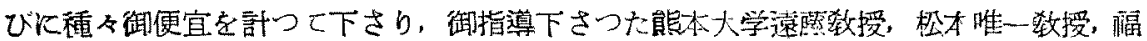
山助敎授に対して謝意を表する。

\section{秋田縣森吉山のブナ地帶及びポドソル地帶 に於ける土壤中の礦物について}

On minerals in the soil of Beech zone and Podosol zone at Moriyoshi-yama, Akita Pref.

萧松四郎 (Shiro Kanematsu)

\section{緒言}

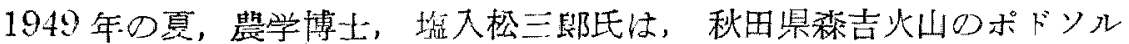
(Podosol) 土壤研劣の為登山世られ，之の際各地带て埰取せし土壤党提

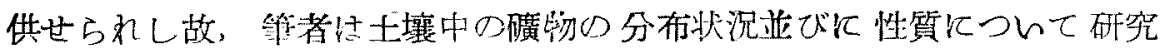

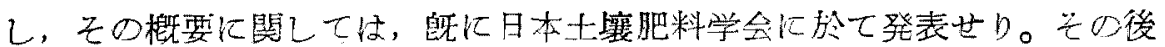

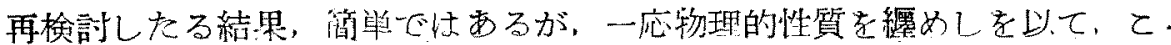
〉に報告する。

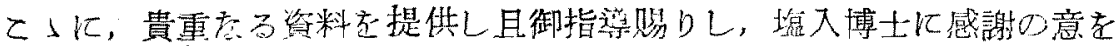
表五。

位 置：森吉山は秋田県 北秋田郡の南東阳住位す一消火山にして，南 は打当川，北け小又川，西は第三紀丘陵と境し，東は燒山氆山の一部と接 せり。

地形及び地質： 森吉山近傍の地質に関しては，大日方順三氏により詳 細に調查が行われ，震贸予防調查合報告第 50 号に発表せら狆居れり。民 の報告によれば，森吉火山の火山活動は第三系中新統に始まり，石森狺

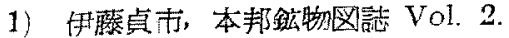

